\title{
A ausência do ensino da computação na Educação Básica e suas consequências para a formação do Licenciando: como ensinar computação sem o uso do computador?
}

\author{
Tamires Maria dos Santos ${ }^{1}$, Keylla Maria de Sá Urtiga Aita ${ }^{1}$, Aline Montenegro \\ Leal Silva ${ }^{1}$, Francisco Renato Lima ${ }^{1}$, Bruna Gabriela de A. Silva ${ }^{1}$ \\ ${ }^{1}$ Universidade Federal do Piaú (UFPI) \\ Centro de Educação Aberta e a Distância (CEAD) \\ Curso de Licenciatura em Computação \\ Tamiresmarial4@outlook.com, keyllaurtiga@ufpi.edu.br, \\ alineleal@ufpi.edu.br, fcorenatolima@hotmail.com, \\ bruna.gabriela.20@hotmail.com
}

\begin{abstract}
The absence of teaching computing in schools in the interior of the State of Piaui has been a challenge experienced by academics of the Degree in Computing courses in their curricular internship. Faced with this reality, engagement and creativity are needed to overcome barriers. This study presents an experiment for teaching computing without the use of a computer, the socalled unplugged activities. The result of the experiment showed that it is possible to teach computing as a science, without the use of the computer, despite the proven limitations, contributing to the dissemination of alternatives for the training experiences of trainees within their teaching practice.
\end{abstract}

Resumo. A ausência do ensino da computação nas escolas do interior do Estado do Piaui têm sido um desafio vivenciado pelos acadêmicos dos cursos de Licenciatura em Computação em seu estágio curricular. Ante a esta realidade é necessário engajamento e criatividade para transpor as barreiras. O presente estudo apresenta um experimento para o ensino da computação sem o uso do computador, as denominadas atividades desplugadas. $O$ resultado do experimento demonstrou que é possível ensinar a computação como ciência, sem o uso do computador, a despeito das limitações comprovadas, contribuindo para a disseminação de alternativas para as vivências de capacitação dos estagiários dentro da sua prática docente.

\section{Introdução}

Diante de um mundo cada vez mais tecnológico, a escola como espaço de ensinar e aprender precisa estar preparada e aberta às inovações que as Tecnologias Digitais da Informação e Comunicação (TDICs) promovem. Nesse sentido, faz-se necessário tornar o ensino da computação uma realidade na Educação Básica, visto a sua importância para o processo de ensino aprendizado contemporâneo e a capacidade de transformar o ambiente de ensino tradicional em um local dinâmico e inovador. As Diretrizes para ensino de Computação na Educação Básica, SBC (2017) afirmam que:

Computação contribui na formação do jovem do século XXI pois: Permite a compreensão plena do mundo, cada vez mais conectado e imerso em tecnologias digitais essencialmente; Aumenta a capacidade de aprendizagem e resolução de problemas dos alunos, provendo novas formas de expressão e pensamento; Serve como ferramenta de apoio ao aprendizado das demais disciplinas. (SBC,2017, p.6). 
A despeito desta incontestável realidade, no Brasil, o ensino da computação nas escolas ainda não integra o conjunto de disciplinas obrigatórias na Base Nacional Curricular comum (BNCC) [Brasil 2021], prejudicando os estagiários das licenciaturas em computação em suas práticas pedagógicas e afastando os alunos de um processo de aprendizagem mais dinâmico e inovador, por meio do uso das tecnologias. Esta realidade torna-se ainda mais evidente quando vivenciamos o cotidiano das escolas públicas piauienses, onde além da resistência dos professores e gestores das escolas quanta a inclusão do graduando no ambiente educacional, enfrenta-se a carência de infraestrutura física e tecnológica; tornando a atuação do licenciando em computação um grande desafio.

Ante a realidade exposta e também vivenciada pelo autor por ocasião dos estágios supervisionados do curso, há um questionamento que norteou esta pesquisa: como ensinar computação sem o uso do computador? Desse modo, a pesquisa objetiva testar estratégias que podem ser desenvolvidas no campo de estágio a fim de demonstrar que é possível ensinar a computação como ciência, por meio das atividades denominadas "desplugadas"; contribuindo assim para formação e capacitação dos professores de computação para trabalharem em cenários de escassez de recursos tecnológicos, bem como despertar o interesse dos alunos pelo raciocínio computacional.

\section{O ensino da Computação na Educação Básica e alternativas "desplugadas"}

A ausência do ensino da computação nas escolas é um grande desafio enfrentado pelo licenciado, visto que muitas escolas não estão preparadas para essa necessidade e ainda permanecem apenas com ensino tradicional e engessado. Lima; Aita; Silva (2019) afirmam:

De modo geral, o primeiro desafio é a falta de escolas para realizar as atividades de estágio, uma vez que, conforme a LDB 9.394/96 o componente curricular Informática não é obrigatório na Educação Básica, portanto, as redes de ensino não se sentem obrigadas a oferecerem tal elemento formativo. (LIMA;AITA; SILVA; 2019 p. 431).

Diante da desobrigação atestada na própria LDB 9.394/96 e exposta na afirmação supracitada, justifica-se o fato de o ensino da computação permanecer ausente na Educação Básica, bem como o pouco interesse das escolas em buscar sua implementação.

Um outro desafio de grande impacto é a falta de recursos didáticos e espaços apropriados na escola, como laboratórios de Informática e rede Internet em plenas condições, que possam constituir-se como possibilidades para a atuação do professor de computação. Nas poucas escolas em que encontramos essa estrutura no Estado do $<$ oculto $>$, ela é precária, insuficiente e mal utilizada.

Diante da falta de políticas públicas e a luta pela inserção da computação da Educação Básica, o licenciado ainda vivência outro desafio no campo de estágio, que é a resistência dos professores quanto a essa disciplina. Nesse sentido Vilarinho (2006) afirma:

Uma questão que circula nos meios educacionais refere-se à resistência de professores a propostas de inovação educacional, especialmente quando estas se referem à inclusão das tecnologias de informação e comunicação (TIC) na sala de aula. (VILARINHO, 2006, p.2)

O autor é objetivo em sua afirmação ao destacar sobre a resistência dos professores quanto a inclusão das tecnologias na sala de aula. Isso ocorre pelo fato de o 
próprio educador desconhecer o ensino da computação como disciplina, e por pensarem que as inovações tecnológicas vão ocupar seu lugar na escola. A própria ausência da Computação nas escolas públicas acaba por contribuir para que professor esteja mais distante dessa inovação.

Diante todo exposto é perceptível que os desafios enfrentados pelo licenciado em computação no campo do estágio estão dentro e fora do ambiente escolar, pois envolve o seu reconhecimento legal para a sua prática em sala de aula

\subsection{Computação Desplugada}

Para além dos aparatos tecnológicos necessários à prática da computação, há uma etapa preliminar de suma importância para o desenvolvimento do raciocínio lógico computacional que pode ser implementada sem o uso do computador. Santos; Gama; Farias (2019) enfatizam que a computação desplugada é um tema que vem crescendo discretamente na educação brasileira, sendo uma alternativa a ser considerada para a inclusão de conceitos de computação e do pensamento computacional dos alunos, principalmente aqueles que estudam em escolas que não possuem estrutura básica para realizar o ensino da computação através do uso dos computadores.

O livro "Computer Science Uplugged" e site (https://csunplugged.org/en/) de Bell et al. (2015) contribuem para a disseminação do pensamento computacional, visto que, possuem um material didático, dinâmico e interativo que favorece o ensino da ciência da computação. Ambas dispensam o uso do computador e são alternativas importantes para a disseminação do pensamento computacional por meio de atividades desplugadas. As desplugadas são eficazes para o ensino da computação, pois permite diversas possibilidades de aplicação, sem necessariamente ter o computador ou estar dentro de uma sala de aula.

Diante da ausência de equipamentos e do ensino da computação nas escolas do interior do estado do Piauí vivenciou-se, na prática, o que relatam Lopes e Ohashi (2019), Castilho; Grebogy e Santos (2019) e Schulz e Schmachtenberg (2017) em seus trabalhos, que é possível ensinar computação como ciência por meio das atividades desplugadas, conforme demonstra-se a seguir.

\section{Metodologia}

Foi realizada revisão da literatura com base nas leituras de artigos provenientes de anais de Workshop de Informática na Escola de 2017 a 2019, Anais do Encontro Virtual de Documentação em Software Livre e Congresso Internacional de Linguagem e Tecnologia Online (2012), Revista E-Curriculum (2006), entre outros. Na sequência, foi realizada uma pesquisa de campo que consistiu no experimento de aplicação das atividades desplugadas com os alunos. Por fim, com auxílio da ferramenta Google Forms, sintetizouse os resultados percebidos na experiência.

Os sujeitos envolvidos na pesquisa foram: uma discente do curso de Licenciatura em Computação da Universidade Federal do Piauí, responsável pelo experimento, professores e seus alunos do Ensino Fundamental. As atividades desplugadas foram realizadas por alunos com idade entre 8 e 12 anos de idade, das redes pública e privada, residentes no município de União (Piauí). 
O experimento foi realizado no mês de novembro de 2020 de forma presencial. A prática foi dividida em 2 grupos: no turno da manhã, com alunos da $2^{\mathrm{a}}$ série, e no turno da tarde, $5^{\mathrm{a}}$ e $6^{\mathrm{a}}$ série. Foram respeitados os protocolos locais impostos pela Vigilância Sanitária em decorrência da pandemia pelo novo coronavírus e assim garantir a segurança de todos os partícipes, conforme apresentado na Figura 1.

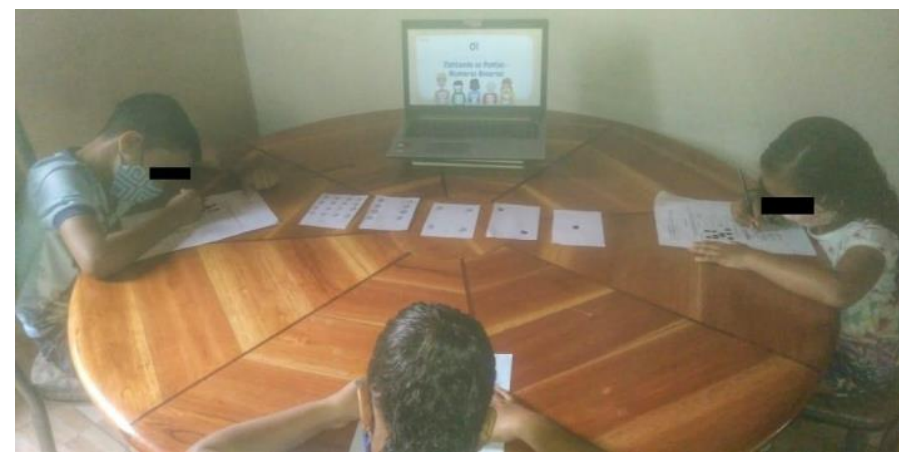

Figura 1: Aplicação das Atividades desplugadas.

Foram trabalhados dois temas do Livro "Computer Science Uplugged" de Bell et al. (2015). Aplicou-se as atividades dos temas Números Binários e Representação das imagens.

\subsection{Atividade Contanto os pontos e Números Binários}

Inicialmente explicou-se aos alunos sobre a computação desplugada, o pensamento computacional e sua importância transversal para o aprendizado das demais disciplinas. Posteriormente, explanou-se sobre o tema números binários, apresentando exemplos e aplicando três questões a respeito da temática proposta. Os alunos deveriam decifrar os números que estavam codificados por meio dos símbolos apresentadas (Figura 2).

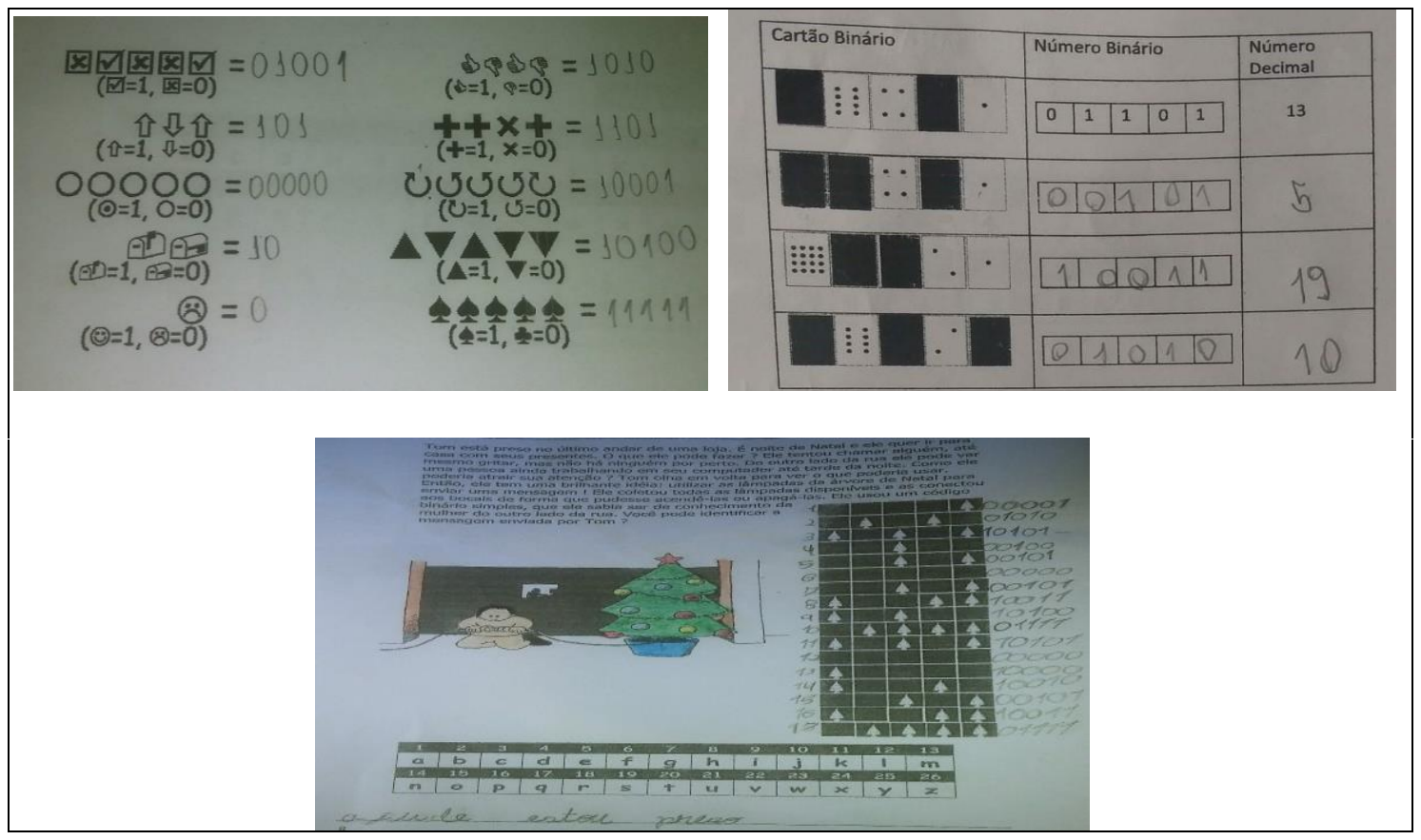

Figuras 2: Atividade Contanto os pontos e Números Binários. 


\subsection{Atividade Colorindo os Números}

Conforme os conceitos adquiridos nas questões anteriores sobre os números binários, foram apresentados aos alunos o tema colorindo os números e demostrado através de exemplos como funciona a representação de uma imagem em um computador. Foi explicado que os quadradinhos em uma imagem de um computador são conhecidos como pixel. Após isso, cada aluno individualmente reproduziu a imagem de acordo com os pixels indicados (Figura 3).

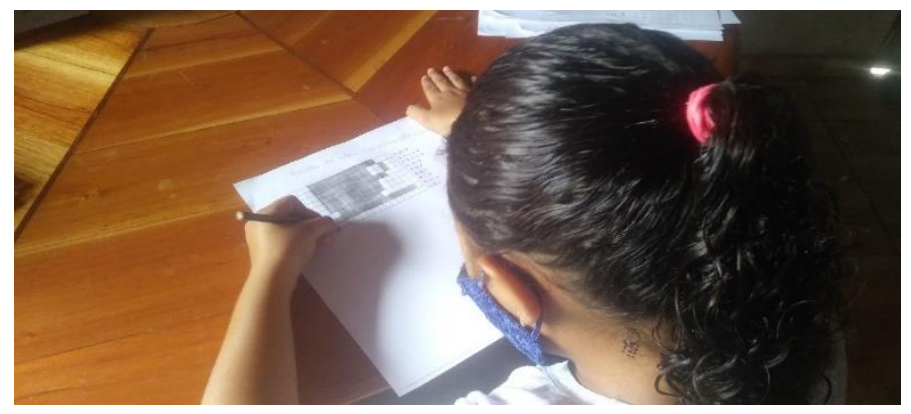

\subsection{Questionário}

Figura 3: Reprodução da Imagem.

A síntese dos resultados do experimento foi realizada por meio do Google Forms, com aplicação de questionário direcionados aos alunos e relatos observacionais subjetivos feitos por mães, professores e executor da pesquisa. Os questionamentos a serem aplicados tinham o objetivo de entender a percepção dos estudantes sobre as atividades desplugadas, bem como do executor, enquanto estagiário do curso de licenciatura em computação, no que tange aos desafios da ausência da computação no campo de estágio.

Posteriormente a realização das atividades e de posse das informações obtidas através do questionário e relatos subjetivos, os dados foram analisados e expostos na seção seguinte.

A variáveis observacionais a serem analisadas: (1) o interesse dos alunos quanto a realização das atividades; (2) o entendimento sobre os conceitos computacionais embutidos na atividade e a (3) completude na realização da tarefa.

\section{Resultados e Discussões}

A Figura 4A comprova o que foi perceptível durante a prática: os alunos mostraram-se entusiasmados para aprender computação sem usar o computador (Variável 1).

Os resultados obtidos na figura 4B demostram que apesar das dificuldades vivenciadas, a maioria dos alunos conseguiu ter um bom desenvolvimento na atividade (Variável 3).

Diante das observações realizadas e dos resultados obtidos foi possível identificar o engajamento dos alunos para a realização das atividades e o nível de compressão dos mesmo sobre os temas trabalhados nas questões (Variável 2). 


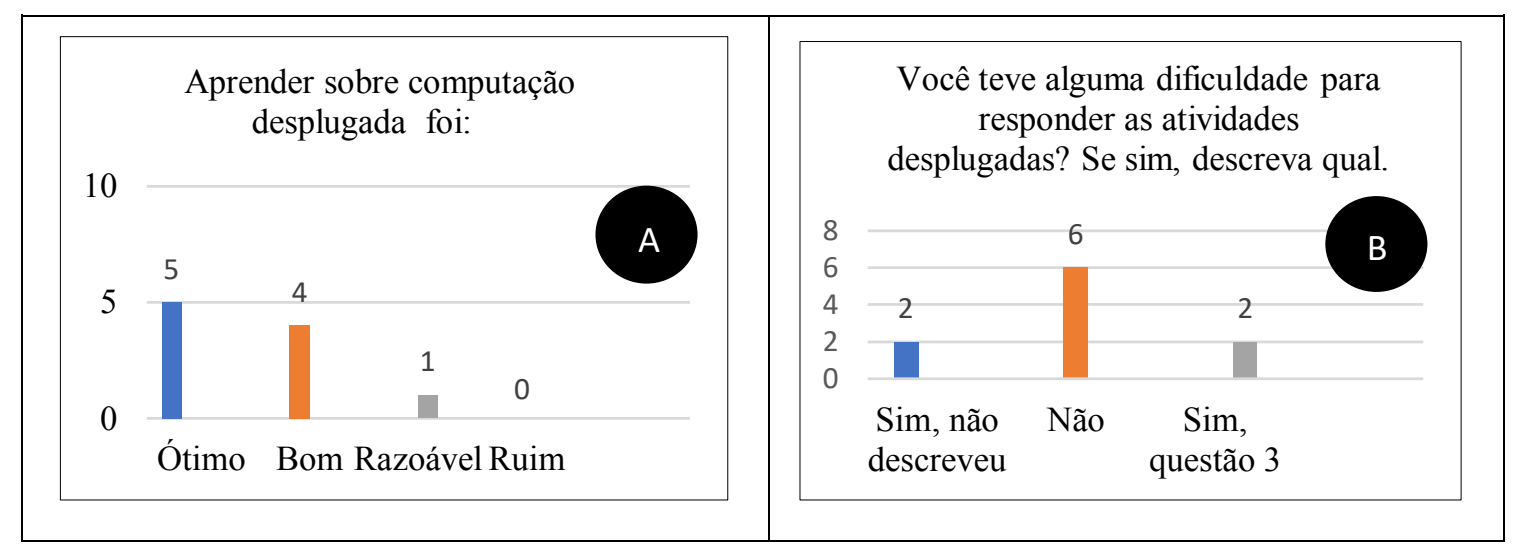

Figura 4: Questões 1 e 2.

A Figura $5 \mathrm{~A}$ demonstra as possibilidades que as atividades desplugadas permitem, visto as mesmas podem ser realizadas com o auxílio de alguém sem conhecimento de computação ou até mesmo sozinho. A figura 5B evidencia que todos os alunos que participaram do experimento aprenderam a codificação utilizada pelo computador (Variável 2). Isso confirma o que se percebeu durante as experiencias com as atividades, visto que os alunos se manifestaram curiosos para aprender sobre os números binários.

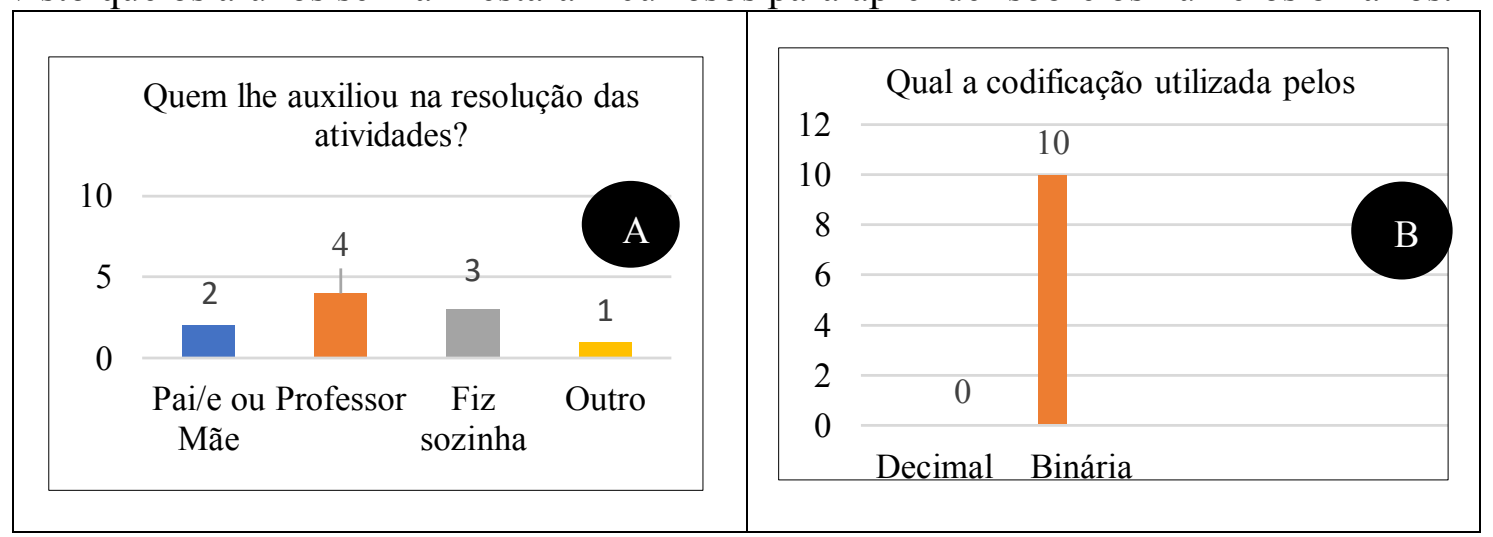

Figura 5: Questões 3 e 6.

Como disposto na Tabela 1, os alunos entrevistados acharam divertido essa nova forma de aprender. Justificando que foi bom e fácil, pois aprenderam algo novo, e além disso foi uma novidade e interessante.

Legitimando esses resultados, a professora titular salientou que percebeu um grande interesse por parte dos alunos e, principalmente, muita curiosidade ao desenvolver as atividades (Variável 1). Defende também que foi um conhecimento adicional relevante para as crianças, uma proposta de ensino valido e altamente produtiva. Uma maneira diferente de se trabalhar e assim desenvolver vários campos e principalmente a criatividade do aluno em si.

Tabela 1- Você achou divertido essa nova forma de aprender?

Você achou divertido essa nova forma de aprender? Justifique sua resposta.

\begin{tabular}{|l|l|}
\hline Aluno A & Sim, é fácil. \\
\hline Aluno B & Sim, porque eu aprendi novas tarefas. \\
\hline Aluno C & Sim. porque aprendi algo novo. \\
\hline Aluno D & Sim, porque foi mais fácil de absorver os conteúdos. \\
\hline Aluno E & Sim, eu achei bom. \\
\hline
\end{tabular}




\begin{tabular}{|l|l|}
\hline Aluno F & Sim, pois aprendi uma coisa nova. \\
\hline Aluno $\mathrm{G}$ & Eu achei legal, aprendi muito. \\
\hline Aluno H & Sim, porque aprendi uma coisa nova. \\
\hline Aluno I & Sim achei, pois foi uma novidade para mim. \\
\hline Aluno J & Sim. Porque eu achei interessante. \\
\hline
\end{tabular}

Subjetivamente os alunos descreveram as experiencias com as atividades desplugadas como "legal", "diferente", "interessante" e "divertido", pois aprenderam algo novo. Diante do resultado alcançado e das observações realizadas, notou-se que antes e durante a aplicação, os alunos mostraram-se ansiosos e interessados. De acordo com a professora titular foi nítido a euforia demostrada pelos alunos ao realizar cada questão e a satisfação após a execução das atividades propostas, pois sem dúvidas foi algo novo vivenciado por eles.

Como fechamento, a professora titular descreveu subjetivamente suas impressões em forma de relato:

Diante da aplicação das atividades desplugadas, foi perceptível o envolvimento dos alunos na realização do que foi proposto, apesar de serem aluno de diferente faixa etária todos conseguiram se desenvolver produtivamente a realizar as atividades propostas. Particularmente adorei a proposta de ensino diferente as atividades desplugadas e considero algo de grande produção a ser realizada dentro das escolas e no currículo escolar.

\section{Conclusão}

A ausência do ensino da computação nas escolas públicas do Piauí é um grande desafio vivenciado pelo licenciado no campo de estágio, trazendo consequências para a prática do acadêmico. Há muitas barreiras existentes para que de fato o ensino da computação esteja inserido na Educação Básica, visto que não há aparato tecnológico nas escolas, bem como ainda não há instrumento legal constituído.

A presente pesquisa demonstrou que os alunos podem estudar conceitos da ciência da computação sem o uso do computador, por meio das denominadas atividades desplugadas, aprendendo a computação como ciência, a despeito das limitações tecnológicas comprovadas. Os resultados apresentados são positivos e evidenciam que o licenciandos em computação nos seus campos de estágio curricular obrigatório podem utilizar uma alternativa simples, barata e eficiente para pôr em prática o ensino da computação e assim superar as possíveis barreiras existentes no campo educacional, onde não haja recursos tecnológicos disponíveis. Deste modo, o uso das atividades desplugadas podem contribuir para formação e capacitação de estagiários dentro da sua prática em sala de aula.

Com os relatos subjetivos obtidos e as observações feitas durante a realização da pesquisa de campo torna-se evidente as possibilidades que atividades desplugadas permitem aos alunos, para além do aprendizado é uma maneira divertida de aprender. Constitui-se uma importante alternativa a ser utilizada dentro das escolas, visto que instiga a curiosidade para aprender algo novo, além de ser uma alternativa útil e que aguça a criatividade do aluno para o ensino da computação. 


\section{Referências}

Bell, T.; Witten, I.; Fellows, M. (2011). “Computer Science Unplugged - Ensinando Ciência da Computação sem o uso do Computador". Disponível em: http://csunplugged.org/. Acesso em 8 jul. 2020.

Brasil. Base Nacional Comum Curricular (BNCC). (2018a). Educação é a Base: Educação Infantil e Ensino Fundamental. Brasília: MEC/CONSED/UNDIME. 472 ps. Disponível em:

http://basenacionalcomum.mec.gov.br/wpcontent/uploads/2018/02/ bncc-20dezsite.pdf >. Acesso em: 05 jan. 2021.

Castilho, M. A.; Grabogy, E. C., Santos, I. (2019). O Pensamento Computacional no Ensino Fundamental I. In: VIII Congresso Brasileiro de Informática na Educação (CBIE 2019) e Anais do XXV Workshop de Informática na Escola (WIE 2019),p. 461470. 2019. Disponível em: $<$ https://www.brie.org/pub/index.php/wie/article/view/8533>. Acesso em:04 de maio de 2020

Lacerda, M. (2012). Informática como disciplina obrigatória na Educação Básica. In: IX Encontro Virtual de Documentação em Software Livre e VI Congresso Internacional de Linguagem e Tecnologia Online. Anais... Volume 1, Número 1. Disponível em: < http://evidosol.textolivre.org/ > Acesso em: 05 de maio de 2020.

Lima, F. R.; Aita, K. M. de S. U.; Silva, A. M. L. (2019). Os desafios da implementação do curso de Licenciatura em Computação do Centro de Educação Aberta e a Distância/Universidade Federal do Piauí (CEAD/UFPI) e as contribuições para o ensino de Informática na Educação Básica. In: LIMA, Francisco Renato (Org.). Os professores e suas experiências de formação, pesquisa e ensino. São Carlos: Pedro \& João Editores, p. 413-445.

Lopes, A.D.L; Ohashi, A.G.R. (2019). Estimular o Pensamento Computacional através da Computação desplugada aos alunos do Ensino Fundamental. In: VIII Congresso Brasileiro de Informática na Educação (CBIE 2019) e Anais do XXV Workshop de Informática na Escola (WIE 2019). Instituto Federal de Ciência e Tecnologia do Estado do Pará. Castanhal - PA. Disponível em: $<$ https://www.brie.org/pub/index.php/wie/article/view/8529/6102>. Acesso em: 04 de maio de 2020.

Santos, A.; Gama, R.; Farias, C. (2019). Computação desplugada no ensino da Computação no Brasil: um mapeamento sistemático da literatura. In: ESCOLA REGIONAL DE COMPUTAÇÃO BAHIA, ALAGOAS E SERGIPE (ERBASE), 2019, Ilhéus. Anais [...]. Porto Alegre: Sociedade Brasileira de Computação, p. 565574.

SchulZ, J. M.; Schmachtenberg, R. F. (2017). Construindo o Pensamento Computacional: experiência com o desenvolvimento e aplicação de materiais didáticos desplugadas. In: Seminário Institucional do PIBID/UNISC. VI Seminário Nacional da Infância e Educação. Disponível em: $<$ https://online.unisc.br/acadnet/anais/index.php/pibid_unisc/article/view/17788/4 646> Acesso em :25 de maio de 2020.

Vilarinho, L. R. G. (2006). Uso do Computador e Rede na Prática Pedagógica: uma Visão de Docentes do Ensino Estadual. Revista E-Curriculum, v. 2, n. 3, dezembro 2006. 